\title{
Assessment of techniques for measurement of blood pressure in infants and children
}

\author{
A. M. ELSEED, E. A. SHINEBOURNE, and M. C. JOSEPH \\ From the Paediatric Department, Brompton Hospital, Fulham Road, London
}

\begin{abstract}
Elseed, A. M., Shinebourne, E. A., and Joseph, M. C. (1973). Archives of Disease in Childhood, 48, 932. Assessment of techniques for measurement of blood pressure in infants and children. Indirect techniques for blood pressure (BP) measurement in infants and children include palpation, auscultation, flush, and the Doppler shift technique. In a double-blind controlled trial these indirect methods were compared to direct intra-arterial measurements. 22 children, aged 1 to 11 years, had their BP measured by a nurse and a doctor each using the four indirect techniques in a randomized order while a third observer recorded intra-arterial pressures. Nurses and doctors obtained similar readings. There was no significant difference between direct measurements and pressures obtained by the Doppler shift technique, but other techniques underestimated systolic pressure: auscultation $3 \cdot 6 \pm 7 \cdot 6 \mathrm{mmHg}$ (mean systolic difference \pm SD) $\mathrm{P}<0.05$; palpation $10.9 \pm 7.9, \mathrm{P}<0.001$; flush $40 \cdot 1 \pm 11 \cdot 6, \mathrm{P}<0 \cdot 001$. The Doppler technique was also assessed in situations where it was impossible to record lower limb systolic pressures by other indirect methods. Lower limb BP was successfully recorded in 10 of 12 patients with coarctation of the aorta and in 4 obese infants with absent pedal pulses.
\end{abstract}

Measurement of systemic blood pressure in infants and young children may be difficult. Intra-arterial recording is accurate but is not suitable for routine use. Attempts have been made to compare blood pressure recordings obtained by the various indirect methods with intra-arterial measurements (Van Bergen et al., 1954; Gunteroth and Nadas, 1955; Moss et al., 1957; Moss and Adams, 1964; Hernandez, Goldring, and Hartmann, 1971), but few of these studies were carried out in a controlled, double-blind manner, and in none were all the techniques evaluated in a randomized order. Not only may knowledge of the intra-arterial pressure prejudice an observer using an indirect technique, but there is a tendency to regard the first of a series of repeated measurements as correct (Armitage, 1971).

In paediatric practice there are situations where it is particularly difficult to record the blood pressure. A relatively common example is measurement of lower limb blood pressure in infants with coarctation of the aorta, but similar difficulties are experienced in obese infants, after arteriotomy, and in the arm after a Blalock-Taussig shunt. Here the most

Received 4 June 1973. accurate noninvasive technique has yet to be established. The dual purpose of this study was to assess the accuracy of palpation, flush, auscultation, and Doppler techniques when compared to intraarterial measurements and to establish which methods can be used in the different situations mentioned.

\section{Material and methods}

Blood pressure was measured in 22 children, 1 to 11 years of age, in the period immediately after major cardiovascular surgery. All patients had intra-arteria! lines in radial or brachial artery to assist in routine postoperative management. Clinical details of patients are shown in Table I. Cuff size was chosen according to age as recommended by Moss and Adams (1965) and the American Heart Association (1967). The same cuff size was used for upper and lower limbs. Intra-arterial blood pressure was measured in one arm using a heparinized saline filled indwelling intra-arterial polyethylene cannula (ID $0 \cdot 70 \mathrm{~mm}$ ) and Bell and Howell pressure transducer (4-327-L223). The pressure was displayed on a Patient Automated Monitor (SE Laboratories, Amplifier type SEM 312).

When the patient's cardiovascular status was stable after return to the intensive care ward, systolic blood pressure was recorded from the contralateral arm by a doctor and a trained nurse. Each took measurements by 
TABLE I

Clinical data and cuff size

\begin{tabular}{|c|c|c|c|c|}
\hline $\begin{array}{c}\text { Case } \\
\text { no. }\end{array}$ & $\begin{array}{l}\text { Age } \\
\text { (yr) }\end{array}$ & $\begin{array}{c}\text { Height } \\
\text { (cm) }\end{array}$ & $\begin{array}{c}\text { Weight } \\
\text { (kg) }\end{array}$ & $\begin{array}{c}\text { Cuff size } \\
(\mathrm{cm})\end{array}$ \\
\hline $\begin{array}{r}1 \\
2 \\
3 \\
4 \\
5 \\
6 \\
7 \\
8 \\
9 \\
10 \\
11 \\
12 \\
13 \\
14 \\
15 \\
16 \\
17 \\
18 \\
19 \\
20 \\
21 \\
22\end{array}$ & $\begin{array}{l}3 \\
4 \\
8 \\
8 \\
6 \\
2 \cdot 5 \\
3 \\
9 \\
2 \cdot 5 \\
9 \\
7 \cdot 5 \\
6 \\
10 \cdot 5 \\
10 \\
2 \cdot 5 \\
1 \\
9 \\
6 \cdot 5 \\
4 \cdot 5 \\
5 \cdot 5 \\
5 \\
5\end{array}$ & $\begin{array}{r}97 \\
94 \\
121 \\
137 \\
115 \\
82 \\
92 \\
130 \\
95 \\
136 \\
126 \\
105 \\
135 \\
123 \\
100 \\
64 \\
139 \\
115 \\
100 \\
108 \\
116 \\
109\end{array}$ & $\begin{array}{r}10 \cdot 8 \\
12 \cdot 4 \\
21 \cdot 7 \\
32 \cdot 0 \\
16 \cdot 5 \\
12 \cdot 5 \\
11 \cdot 4 \\
27 \cdot 6 \\
13 \cdot 2 \\
30 \cdot 5 \\
22 \cdot 5 \\
15 \cdot 2 \\
26 \cdot 0 \\
21 \cdot 0 \\
13 \cdot 7 \\
8 \cdot 5 \\
32 \cdot 2 \\
20 \cdot 0 \\
14 \cdot 3 \\
17 \cdot 3 \\
16 \cdot 4 \\
14 \cdot 4\end{array}$ & $\begin{array}{l}5 \\
5 \\
7 \\
9 \cdot 5 \\
7 \\
5 \\
5 \\
9 \cdot 5 \\
5 \\
9 \cdot 5 \\
7 \\
7 \\
9 \cdot 5 \\
7 \\
5 \\
5 \\
9 \cdot 5 \\
7 \\
5 \\
7 \\
7 \\
7\end{array}$ \\
\hline
\end{tabular}

auscultation, Doppler, flush, and palpation, the order in which they were applied being randomized. Neither doctor nor nurse knew the blood pressure recorded directly, nor did they know each other's readings. The direct intra-arterial systolic blood pressure simultaneously recorded was noted by a third observer who was in turn unaware of the indirect measurements.
The same technique was followed each time blood pressure was measured indirectly. After checking the zero of the mercury column, the sphygmomanometer cuff was completely deflated before applying it snugly around the upper arm. It was then inflated to a pressure of $250 \mathrm{mmHg}$. The pressure was allowed to drop at a rate not faster than 5-7 $\mathrm{mmHg} / \mathrm{sec}$ and the first sound heard over the brachial artery by auscultation or by the Doppler machine ${ }^{\star}$ was taken as the end point. Similarly, the first impulse felt was recorded as systolic pressure by palpation. For the flush method the hand was raised above the level of the heart and firmly squeezed manually until it was pale and then the cuff, applied proximal to the wrist, was inflated. Deflation was at the rate of $5-7 \mathrm{mmHg} / \mathrm{sec}$ and the first sign of flushing seen in an adequately lighted room was taken as the flush pressure. Manual squeezing of the hand was unsuccessful in some patients and a wide elastic band was used. Two observers were needed to take the flush pressure, one observing the mercury column and the other, who was unaware of the height of the mercury column, observing the patient's hand for the end point.

Using the same indirect technique and applying the cuff above the ankle, lower limb blood pressure was measured in 12 children with coarctation of the aorta in all but one of whom the diagnosis was later confirmed at cardiac catheterization or operation (Table III). Lower limb pressures were also recorded in 3 obese infants and 1 with aortic stenosis, in all of whom pedal pulses were absent and femoral pulses were reduced. Lower limb

$\star$ Parks Electronics Laboratory. Model No. 802. Distributed in U.K. by Instrumentarium Ltd.

TABLE II

Direct and indirect blood pressure measurements

\begin{tabular}{|c|c|c|c|c|c|c|c|c|c|c|}
\hline \multirow{2}{*}{$\begin{array}{l}\text { Case } \\
\text { no. }\end{array}$} & \multicolumn{2}{|c|}{$\begin{array}{c}\text { Direct BP } \\
(\mathrm{mmH})\end{array}$} & \multicolumn{4}{|c|}{$\begin{array}{c}\text { BP (mmHg) } \\
\text { by nurse }\end{array}$} & \multicolumn{4}{|c|}{$\begin{array}{l}\text { BP }\left(\mathrm{mmHg}^{\mathrm{m}}\right) \\
\text { by doctor }\end{array}$} \\
\hline & Systolic & Mean & Auscultation & Doppler & Flush & Palpation & Auscultation & Doppler & Flush & Palpation \\
\hline $\begin{array}{r}1 \\
2 \\
3 \\
4 \\
5 \\
6 \\
7 \\
8 \\
9 \\
10 \\
11 \\
12 \\
13 \\
14 \\
15 \\
16 \\
17 \\
18 \\
19 \\
20 \\
21 \\
22\end{array}$ & $\begin{array}{r}110 \\
110 \\
120 \\
130 \\
120 \\
100 \\
110 \\
115 \\
110 \\
120 \\
115 \\
110 \\
120 \\
110 \\
100 \\
80 \\
130 \\
110 \\
110 \\
120 \\
110 \\
115\end{array}$ & $\begin{array}{l}- \\
- \\
- \\
- \\
- \\
- \\
- \\
- \\
- \\
- \\
80 \\
90 \\
75 \\
55 \\
80 \\
60 \\
85 \\
65 \\
90 \\
90\end{array}$ & $\begin{array}{r}100 \\
95 \\
110 \\
125 \\
100 \\
95 \\
112 \\
115 \\
117 \\
113 \\
110 \\
110 \\
110 \\
116 \\
105 \\
80 \\
125 \\
110 \\
110 \\
125 \\
108 \\
110\end{array}$ & $\begin{array}{r}100 \\
95 \\
102 \\
126 \\
105 \\
100 \\
108 \\
120 \\
115 \\
123 \\
110 \\
118 \\
115 \\
115 \\
110 \\
75 \\
130 \\
105 \\
110 \\
118 \\
112 \\
110\end{array}$ & $\begin{array}{c}65 \\
65 \\
75 \\
65 \\
80 \\
60 \\
80 \\
60 \\
62 \\
78 \\
\star \\
80 \\
70 \\
70 \\
80 \\
48 \\
75 \\
68 \\
70 \\
62 \\
55 \\
70\end{array}$ & $\begin{array}{r}95 \\
85 \\
110 \\
104 \\
100 \\
90 \\
110 \\
105 \\
112 \\
120 \\
98 \\
105 \\
105 \\
98 \\
85 \\
75 \\
116 \\
105 \\
105 \\
110 \\
105 \\
110\end{array}$ & $\begin{array}{r}105 \\
115 \\
105 \\
115 \\
110 \\
90 \\
110 \\
110 \\
115 \\
125 \\
110 \\
120 \\
120 \\
105 \\
100 \\
85 \\
130 \\
105 \\
105 \\
110 \\
86 \\
110\end{array}$ & $\begin{array}{r}110 \\
115 \\
105 \\
115 \\
116 \\
95 \\
110 \\
110 \\
110 \\
125 \\
110 \\
115 \\
115 \\
108 \\
105 \\
85 \\
130 \\
100 \\
100 \\
120 \\
84 \\
115\end{array}$ & $\begin{array}{l}65 \\
85 \\
80 \\
70 \\
80 \\
65 \\
85 \\
50 \\
68 \\
85 \\
\star \\
85 \\
80 \\
70 \\
80 \\
45 \\
90 \\
65 \\
65 \\
60 \\
65 \\
80\end{array}$ & $\begin{array}{r}85 \\
100 \\
100 \\
110 \\
90 \\
90 \\
100 \\
110 \\
108 \\
115 \\
112 \\
110 \\
105 \\
100 \\
85 \\
75 \\
120 \\
105 \\
105 \\
100 \\
90 \\
110\end{array}$ \\
\hline
\end{tabular}


TABLE III

Upper and lower limb blood pressure in patients with coarctation of aorta

\begin{tabular}{|c|c|c|c|c|}
\hline \multirow{2}{*}{$\begin{array}{c}\text { Case } \\
\text { no. }\end{array}$} & \multirow{2}{*}{ Age } & \multirow{2}{*}{$\frac{\begin{array}{c}\text { Upper limb BP } \\
(\mathrm{mmHg})\end{array}}{\text { Doppler }}$} & \multicolumn{2}{|c|}{$\begin{array}{c}\text { Lower limb BP } \\
(\mathrm{mmHg})\end{array}$} \\
\hline & & & Doppler & Flush \\
\hline $\begin{array}{l}26 \\
27 \\
28 t \\
29 \\
30 \\
31 \\
32 \\
33 \\
34\end{array}$ & $\begin{array}{l}8 \mathrm{yr} \\
2 \mathrm{wk} \\
6 \mathrm{wk} \\
6 \mathrm{mth} \\
1 \mathrm{wk} \\
5 \mathrm{wk} \\
6 \mathrm{mth} \\
2 \cdot 5 \mathrm{yr} \\
6 \mathrm{yr} \\
5 \mathrm{wk} \\
4 \mathrm{yr} \\
4 \mathrm{mth} \\
4 \mathrm{yr} \\
8 \mathrm{yr} \\
2 \mathrm{wk} \\
9 \mathrm{mth}\end{array}$ & $\begin{array}{c}155 \\
90 \\
170 \\
190 \\
120 \\
140 \\
? \\
160 \\
140 \\
120 \\
140 \\
130 \\
160 \\
112 \\
160 \\
135\end{array}$ & $\begin{array}{r}120 \\
55 \\
50 \\
50 \\
? \\
? \\
? \\
? \\
100 \\
90 \\
95 \\
80 \\
110 \\
86 \\
85 \\
100\end{array}$ & $\begin{array}{c}80 \\
30 \\
25 \\
- \\
70 \\
80 \\
\mathrm{ND} \\
80 \\
40 \\
60 \\
65 \\
50 \\
80 \\
\text { ND } \\
55 \\
\text { ND }\end{array}$ \\
\hline
\end{tabular}

*Patient recoarcted on two occasions.

†Clinical diagnosis-patient not catheterized.

ND, not done.

blood pressures could not be recorded by palpation or conventional auscultation in any of these patients.

\section{Results}

The direct systolic and mean blood pressure readings and the results obtained by doctors and nurses each using the four indirect techniques are shown in Table II.

Table III shows the lower and upper limb blood pressures in the 12 children with coarctation of the aorta, and Table IV the lower limb blood pressure in 3 obese infants and 1 with aortic stenosis.

All indirect methods, except Doppler, gave results significantly lower than intra-arterial pressures. No significant difference was found when the Doppler technique was used. The significance of the mean differences between indirect and direct techniques is shown in Table $\mathrm{V}$ where it is apparent
TABLE IV

Lower limb blood pressure in 3 obese infants and infant with aortic stenosis

\begin{tabular}{c|c|c|c}
\hline \multirow{2}{*}{$\begin{array}{c}\text { Case } \\
\text { no. }\end{array}$} & $\begin{array}{c}\text { Age } \\
(\mathrm{mth})\end{array}$ & \multicolumn{2}{|c}{ Lower limb BP (mmHg) } \\
\cline { 2 - 3 } & & Doppler & Flush \\
\hline 35 & 7 & 110 & 80 \\
36 & 6 & 90 & 65 \\
37 & 6 & 140 & 85 \\
38 & $1 \star$ & 120 & 90 \\
\hline
\end{tabular}

^Patient with aortic stenosis.

that auscultation more closely approximated to the direct reading than did palpation. The flush technique gave results that were approximately 40 $\mathrm{mmHg}$ lower than the directly measured systolic pressure. There was no significant difference in the results obtained by doctors and nurses.

To determine whether flush pressure correlated more closely with mean or systolic pressure, the rectilinear regressions of flush on mean and flush on systolic pressure were calculated, as were the respective correlation coefficients. The flush pressure showed a significant correlation $(r=0.602$, $P<0.01$ ) with systolic but not mean pressure $(\mathbf{r}=0.333$, NS). Similarly, the regression coefficient of flush on systolic $(\hat{\mathrm{y}}=0 \cdot 52 \mathrm{x}+12 \cdot 7)$ but not on mean pressure $(\hat{y}=0.35 x+40 \cdot 4)$ indicated a slope significantly different from zero, i.e. flush pressure increased significantly with increase in systolic pressure $(t=3 \cdot 2, P<0 \cdot 01)$ but not with increase in mean pressure.

In the 12 patients with coarctation of the aorta the Doppler technique was successfully used to record lower limb blood pressures in all but 2 patients. In 3 obese infants and 1 with aortic stenosis lower limb blood pressures were recorded by the Doppler technique. Where flush pressures were obtained in patients with coarctation, they were significantly lower than pressures obtained by Doppler (mean difference $33 \pm 10: 9 \mathrm{mmHg}$, no. $=9$ ).

TABLE V

Mean differences $(\mathrm{mmHg})$ between direct and indirect measurements

\begin{tabular}{|c|c|c|c|c|c|c|c|c|}
\hline & \multicolumn{4}{|c|}{ Nurses } & \multicolumn{4}{|c|}{ Doctors } \\
\hline & Mean & SD & $t$ & $\mathbf{P}$ & Mean & SD & $\mathbf{t}$ & $\mathbf{P}$ \\
\hline $\begin{array}{l}\text { Auscultation } \\
\text { Doppler } \\
\text { Flush } \\
\text { Palpation }\end{array}$ & $\begin{array}{r}2 \cdot 9 \\
2 \cdot 2 \\
41 \cdot 8 \\
10 \cdot 3\end{array}$ & $\begin{array}{r}6 \cdot 5 \\
7 \cdot 1 \\
10 \cdot 5 \\
7 \cdot 6\end{array}$ & $\begin{array}{r}2 \cdot 10 \\
1 \cdot 45 \\
18 \cdot 17 \\
6 \cdot 36\end{array}$ & $\begin{array}{l}\text { NS } \\
\text { NS } \\
<0.001 \\
<0.001\end{array}$ & $\begin{array}{r}3 \cdot 5 \\
3 \cdot 1 \\
40 \cdot 1 \\
10 \cdot 9\end{array}$ & $\begin{array}{r}7 \cdot 6 \\
7 \cdot 5 \\
11 \cdot 6 \\
7 \cdot 9\end{array}$ & $\begin{array}{r}2 \cdot 21 \\
1 \cdot 92 \\
15 \cdot 80 \\
6 \cdot 45\end{array}$ & $\begin{array}{l}<0.05 \\
\text { NS } \\
<0.001 \\
<0.001\end{array}$ \\
\hline
\end{tabular}

Note: No. $=22$ for all differences. In all cases direct $>$ indirect measurements

NS, not significant. 


\section{Discussion}

This trial was done to compare, under similar conditions, four indirect techniques with direct blood pressure measurements and to find out which technique could best be used in measuring pressures in the upper and lower limbs, especially in patients suspected to have coarctation of the aorta. The results obtained by Doppler shift showed a close correlation ( $r=0.999)$ with intra-arterial measurements, in agreement with the findings of previous workers (Hernandez et al., 1971; Janis, Kemmerer, and Hagood, 1971). The other indirect techniques all showed a significant, though in the case of auscultation small, difference from direct systolic measurements.

To our knowledge, the value of the Doppler technique in measurement of lower limb blood pressures in coarctation of the aorta has not been assessed and the results obtained are encouraging. Whereas measurement of upper limb blood pressure using the Doppler technique presented no difficulty to doctors or nurses even when new to the technique, it was not so simple to measure lower limb pressure, especially in infants with coarctation of the aorta. The difficulties were mainly due to absence of a palpable arterial pulse and accordingly the foot had to be 'scanned' using the transducer to detect dorsalis pedis or posterior tibial pulsation. Then, keeping the transducer over that point, the cuff was inflated and arterial pressure recorded in the usual manner. The procedure took about 5 to 10 minutes, depending on the age of the patient. For babies and infants two observers may be needed, one to restrain the foot and listen for arterial pulsation, and the other to inflate the cuff and record blood pressure. Lower limb blood pressures recorded by Doppler in patients with coarctation were significantly higher than pressures simultaneously recorded by the flush method. This is in keeping with the findings of our controlled trial and with other workers who showed flush pressures to be well below systolic pressures (Gunteroth and Nadas, 1955; Moss et al., 1957; Moss and Adams, 1964). Most nurses had no previous knowledge of either flush or Doppler technique, and all found the latter simpler in practice. In dark-skinned patients and in children with cold limbs the flush pressure was particularly difficult to record. In one patient (Case 11, Table II) a combination of dark skin and low skin temperature $\left(24{ }^{\circ} \mathrm{C}\right)$ made flush pressure recording impossible despite repeated trials. The flush technique has further disadvantages including lack of reproducibility even if the mercury column is released at the same rate. Goldring and Wohltmann (1952) found a difference of up to 20
$\mathrm{mmHg}$ in the same patient at the same rate of release. Sullivan and Kobayashi (1955) recommended that 3 to 5 readings should be taken and averaged since one reading was of little value. We have also noticed this lack of reproducibility using the flush method. The major disadvantage of the technique, however, in our experience is that flush pressure does not equate with mean or systolic pressure, and though some workers consider it to represent mean blood pressure (Gunteroth and Nadas, 1955; Moss et al., 1957; Moss and Adams, 1964), we were unable to confirm this (correlation coefficient $\mathrm{r}=0.33, \mathrm{P}<0.1)$. A closer approximation to systolic pressure was reported by Cappe and Pallin (1952), Goldring and Wohltmann (1952), and Reinhold and Pym (1955), but in our trial the absolute values differed by 35 to $40 \mathrm{mmHg}$ (Table II) and the correlation coefficient ( $r=0.602$, $P<0.01)$, though significant, was not particularly high. The flush technique has so far found application mainly in situations where blood pressure measurement is difficult by auscultation or palpation. We have found the Doppler technique to be a more reliable method for recording both lower and upper limb blood pressure in coarctation of the aorta, in obese infants, and in neonates.

Measurements made by auscultation were significantly lower than direct systolic pressures and 5 to $10 \mathrm{mmHg}$ greater than measurements made by palpation. Van Bergen et al. (1954), in a controlled trial, found both techniques to underestimate direct systolic pressure which was approximated more closely by auscultation. Gunteroth and Nadas (1955) reported measurements made by auscultation to be 3 to $4 \mathrm{mmHg}$ below direct systolic pressure.

In our experience systolic pressure measured by the Doppler technique agreed more closely with direct measurements than the other indirect methods used. In circumstances where blood pressure is difficult to record, the Doppler technique may be the only indirect method that can be used.

We thank the nursing and house staff for their help, and Miss E. Thompson for dealing with the manuscript.

\section{REFERENCES}

American Heart Association (1967). Recommendations for human blood pressure determination by sphygmomanometers. Circulation, 36, 980.

Armitage, P. (1971). Statistical Methods in Medical Research, p. 181. Blackwell, Edinburgh and Oxford.

Cappe, B. E., and Pallin, I. M. (1952). Systolic blood pressure determination in the newborn and infant. Anesthesiology, 13, 648.

Goldring, D., and Wohltmann, H. (1952). Flush method for blood pressure determinations in newborn infants. fournal of Pediatrics, 40, 285.

Gunteroth, W. G., and Nadas, A. S. (1955). Blood pressure measurements in infants and children. Pediatric Clinics of North America, 2, 257. 
Hernandez, A., Goldring, D., and Hartmann, A. F. (1971). Measurement of blood pressure in infants and children by the Doppler ultrasonic technique. Pediatrics, 48, 788.

Janis, K. M., Kemmerer, W. T., and Hagood, C. O. (1971). Doppler blood pressure measurement in infants and small children. Fournal of Pediatric Surgery, 6, 70.

Moss, A. J., and Adams, F. H. (1964). Flush blood pressure and intra-arterial pressure. A comparison of methods in infants. American Fournal of Diseases of Children, 107, 489.

Moss, A. J., and Adams, F. H. (1965). Auscultatory and intraarterial pressure: a comparison in children with special reference to cuff width. Fournal of Pediatrics, 66, 1094.

Moss, A. J., Liebling, W., Austin, W. O., and Adams, F. H. (1957). An evaluation of the flush method for determining blood pressures in infants. Pediatrics, 20, 53.
Reinhold, J., and Pym, M. (1955). The determination of blood pressure in infants by the flush method. Archives of Disease in Childhood, 30, 127.

Sullivan, M. P., and Kobayashi, M. (1955). Evaluation of the flush technique for the determination of blood pressure in infancy. Pediatrics, 15, 84.

Van Bergen, F. H., Weatherhead, D. S., Treloar, A. E., Dobkin A. B., and Buckley, J. J. (1954). Comparison of indirect and direct methods of measuring arterial blood pressure. Circulation, 10, 481 .

Correspondence to Dr. E. A. Shinebourne, Paediatric Department, Brompton Hospital, Fulham Road, London SW3 6HP. 